Original article

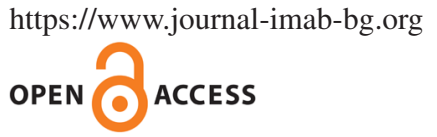

\title{
CONSUMERS' ATTITUDES TOWARDS THE USE OF HERBAL MEDICINES AND HERBAL SUPPLE- MENTS IN NORTHEASTERN BULGARIA
}

\author{
Nadya Agova ${ }^{1}$, Galina Petrova ${ }^{2}$, Svetlana Georgieva ${ }^{1}$, Ivo Kumanov ${ }^{2}$ \\ 1) Department of Pharmaceutical Chemistry, Faculty of Pharmacy, Medical \\ University Varna, Bulgaria. \\ 2) Department of Organization and Economics of Pharmacy, Faculty of Phar- \\ macy, Medical University Varna, Bulgaria.
}

\begin{abstract}
The global use of herbal medicinal products over the past decade has led to the marketing of a large number of herbal medicines and herbal supplements. Although some herbal medicines have promising potential and are widely used, many of them remain untested, and their use also not monitored. The purpose of our study is to investigate the attitudes of consumers in Northeastern Bulgaria to the use of herbal medicines and herbal supplements. The article uses a sociological method for data collection, and descriptive statistics were used to analyze the data and process the results. The study involved 170 users living in Northeastern Bulgaria. Respondents are unevenly rationåd by gender, with women prevailing $-70.60 \%$, men $-29.40 \%$. In terms of age, the rationing is as follows: The largest share of the age group 18-30 years, followed by the age group 41-50 years, and 31-40 years. The respondents are mostly with higher education $-70.40 \%$, with secondary education are $23.90 \%$ and only $5.80 \%$ have secondary special education. Consumers most often buy herbal medicines and supplements to solve health problems related to weak immunity, viral diseases, gastrointestinal problems, insomnia and others. The doctor's and the pharmacist's recommendations have a significant influence on the choice of herbal medicines and food supplements. The positive attitude of the respondents towards them is due to the lack of data on side effects and the benefits they receive. In order to achieve the rational use of herbal medicines and herbal dietary supplements, a better understanding of the impact of food supplements on patients must be a key priority.
\end{abstract}

Keywords: consumers' attitudes, use, herbal medicines, herbal supplements

\section{INTRODUCTION}

Food supplements and herbal medicines are the fastest-growing segments in the pharmaceutical sector. According to IQVIA, it has grown over $10 \%$ over the past few years [1].

Many patients use dietary supplements alone or in combination with conventional drug therapy. When placing medicinal products on the market, special manufactur- ing permits are required, strict control over the entire production process chain, while the preparation reaches the patient.

For food additives, however, all controls are carried out by the Food Safety Agency. There are no specific manufacturing, content and clinical requirements for food supplements. They do not pass through a check on the content by the state. It is necessary to register with the Food Agency, stating the contents of the label and the package leaflet for the patient.

Most dietary supplements are prepared on the basis of plant substances, and they can be manufactured using intact sources or extracts from plants, animals, algae, fungi or lichens, including such examples as ginkgo Biloba, curcumin, cranberry, ginseng, resveratrol, glucosamine, and collagen $[2,3]$. While most of these products have a long history of use in herbalism and various forms of traditional medicine, concerns exist about their actual efficacy, safety, and consistency of quality $[4,5,6]$.

Italy, Germany and Eastern European countries were leading consumers of botanical supplements in 2016, with the European Union market growth forecast to be $\$ 8.7$ billion by 2020 [4]. The growth of sales of registered products such as vitamins, minerals, herbs that increase immunity, probiotics, chondroprotectors and others is increasing every year.

Nutritional supplements are of interest to consumers from almost any age group. Some of them have acute or chronic health problems, and another significant part is healthy people whose purpose is to maintain health.

\section{AIM}

The aim of this study is to investigate the attitudes of consumers on the use of food supplements and herbal medicinal products in the territory of North-East Bulgaria.

\section{MATERIALS AND METHODS}

The article used a sociological method for data collection through a direct anonymous structured survey containing 18 questions. Questions were divided into four purchase frequency blocks and sources of information on nutritional supplements and herbal medicinal products; fac- 
tors that influence the choice of herbal supplements and herbal medicinal products; solution of a specific health effect, benefit and effectiveness of their use; socio-demographic characteristics of consumers. Descriptive statistics were used to analyze the data and process the results. The study was conducted in the time period 01.04 - 30.04.2018 among 170 users.

\section{RESULTS}

The study involved 170 users living in Northeastern Bulgaria. Respondents were unevenly rationåd by gender, with women prevailing - $70.60 \%$, men $-29.40 \%$. In terms of age, the rationing was as follows: The largest share of the age group $18-30$ years with $37.20 \%$, followed by the age group 41-50 years with $26.70 \%$, and $31-40$ years with $25.60 \%$. The share of the age group 51-60 years was insignificant $-7.60 \%$ and only $2.90 \%$ were over 61 years old. The respondents were mostly with higher education $70.40 \%$, with secondary education were $23.90 \%$ and only $5.80 \%$ had secondary special education.

According to our data, most of the respondents $40.30 \%$ state that the pharmacists were the main source of information about herbal medicinal products and nutritional supplements. Other sources of information were information brochures $(36.8 \%)$, Internet $(30.4 \%)$ television advertisements $(29.2 \%)$, doctors (27\%). Only $4.7 \%$ cite newspapers as a way of getting information. The data are presented in Fig. 1.

Fig. 1. Data obtained about the awareness regarding herbal medicinal products and nutritional supplements

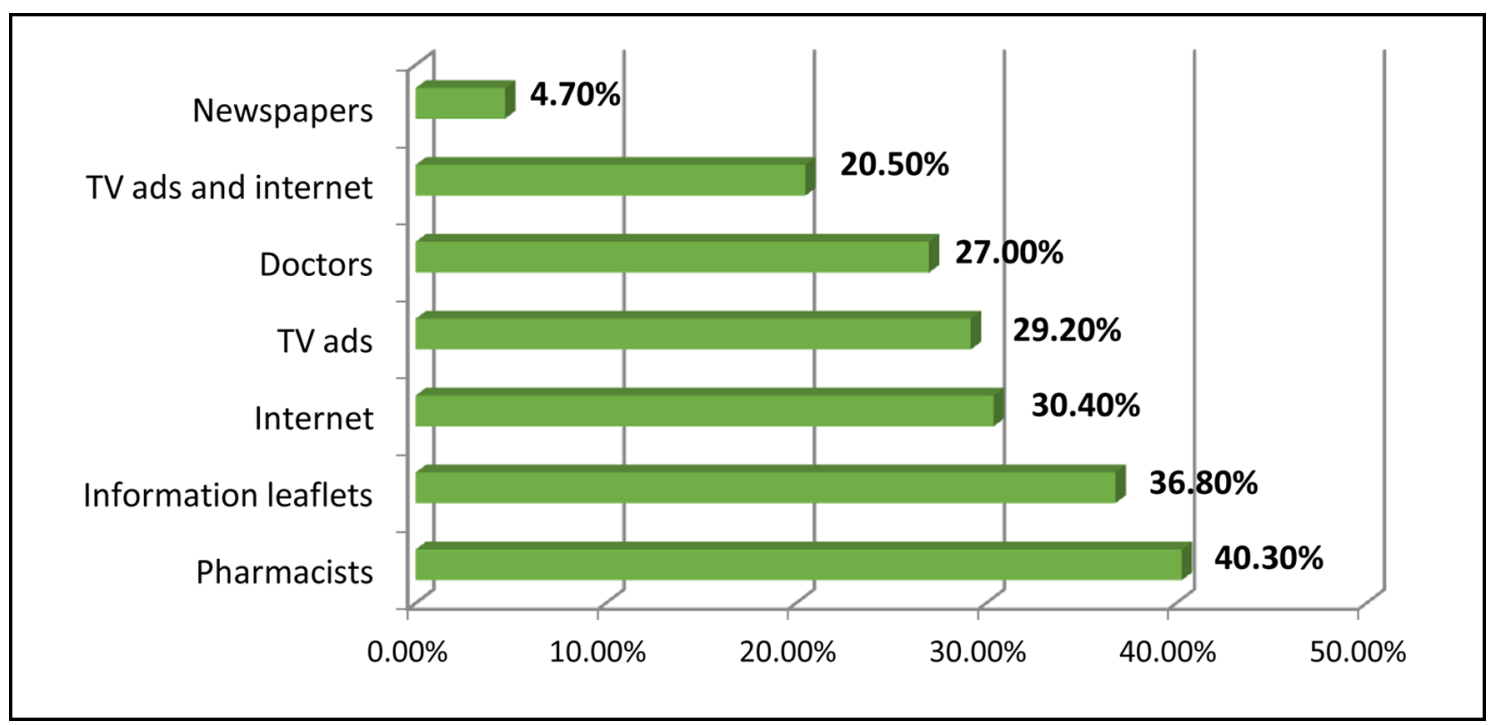

On the question, "How often do you buy herbal and nutritional supplements?" - $42.7 \%$ of respondents answered, that they bought herbal and nutritional supplements once for several months. Each month $28.1 \%$ of respondents bought herbal and nutritional supplements, once a year bought $12.3 \%$ of them; only $8.2 \%$ didn't buy at all. The data are presented in Fig. 2.

Fig. 2. Frequency of purchase of herbal medicinal products and nutritional supplements

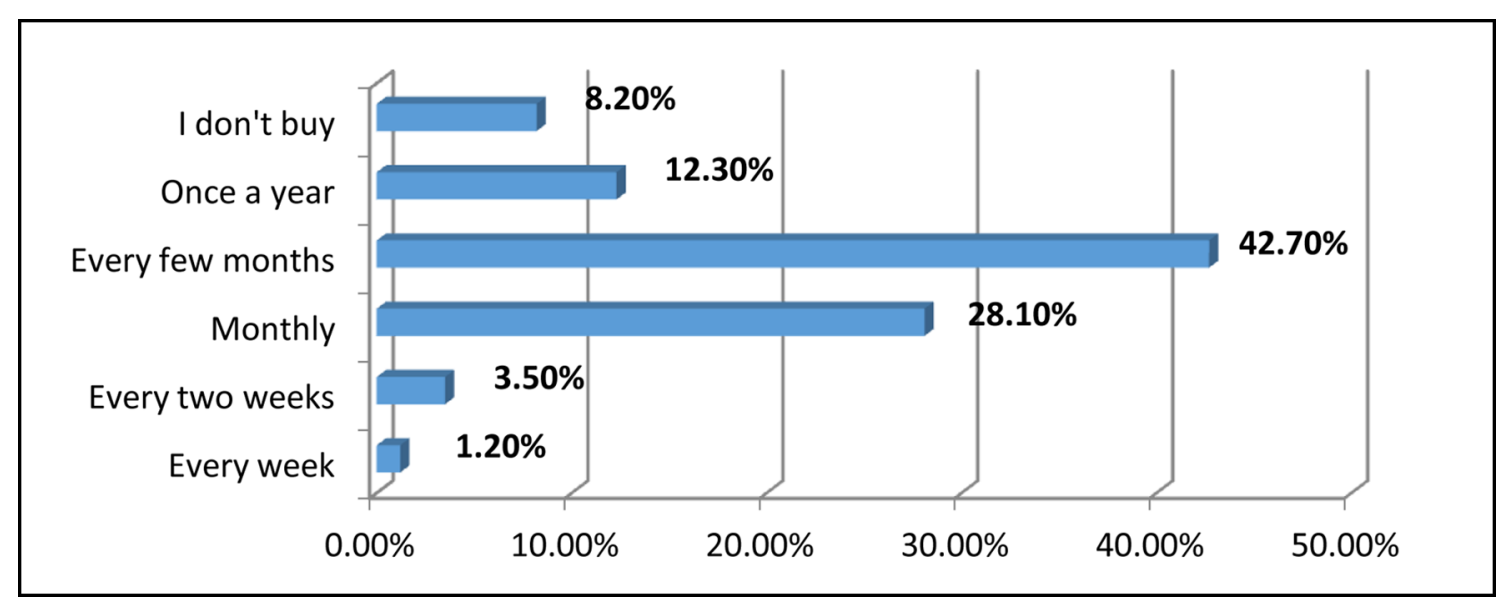


The choice of herbal medicinal products and nutritional supplements was effectively influenced by the doctor's recommendation $(63.3 \%)$, followed by the pharmacist's recommendation $(53.3 \%)$, the information leaflet $(30.8 \%)$. Television advertising (7.7\%) and the Internet (7.7\%) and newspaper advertising (4.7\%) had a low impact. The data are presented in Fig. 3.

Fig. 3. Effective influence on the choice of herbal medicinal products and nutritional supplements

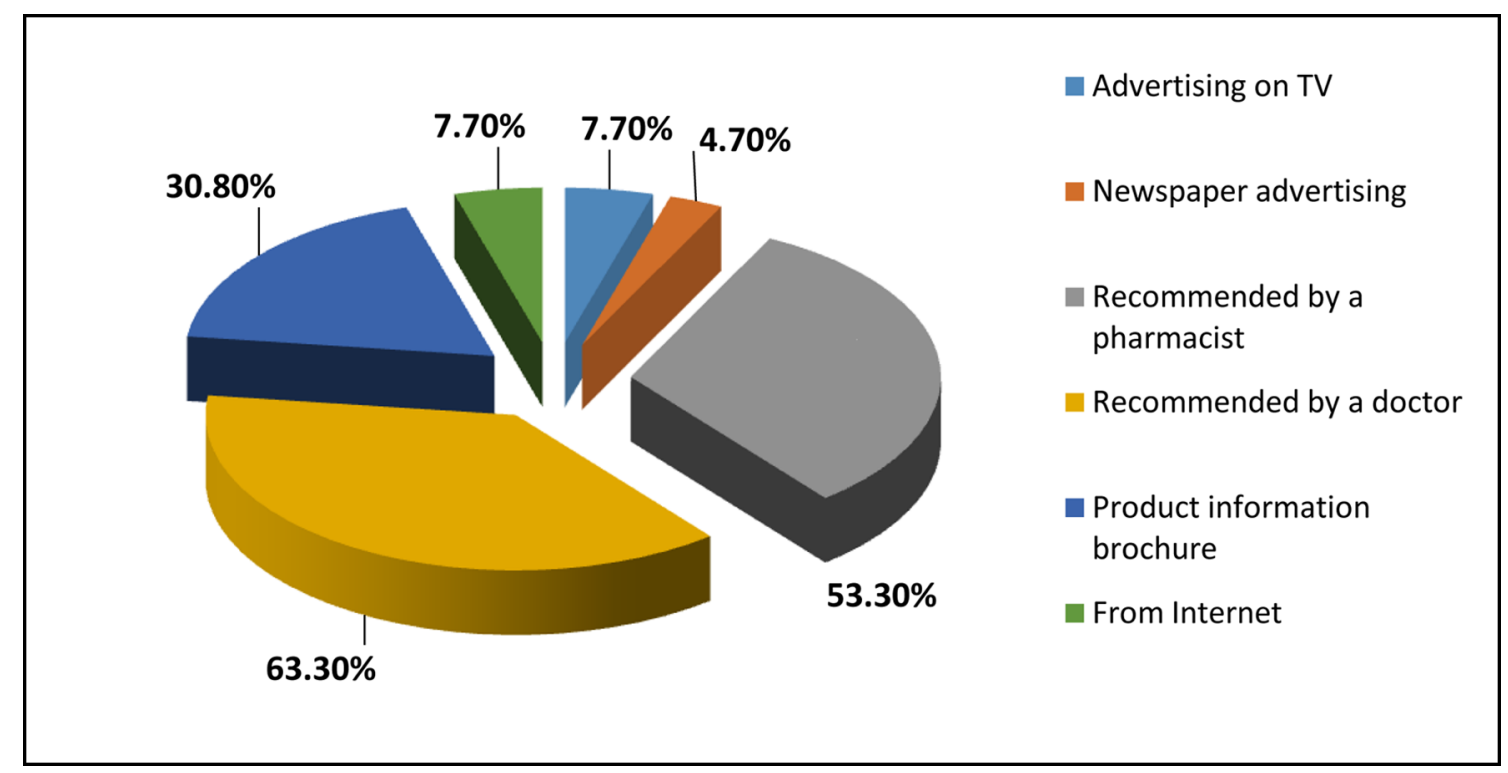

In solving specific health problem consumers most often used herbal medicines and nutritional supplements about boosting immunity $(69 \%)$, in the states of flu and cold $(40.50 \%)$, in gastrointestinal problems $(28.60 \%)$, insomnia $(16.10 \%)$, every other problem $(13.70 \%)$. The data are presented in Fig.4.

Fig. 4. Herbal medicinal products and nutritional supplements used in solving a specific health problem

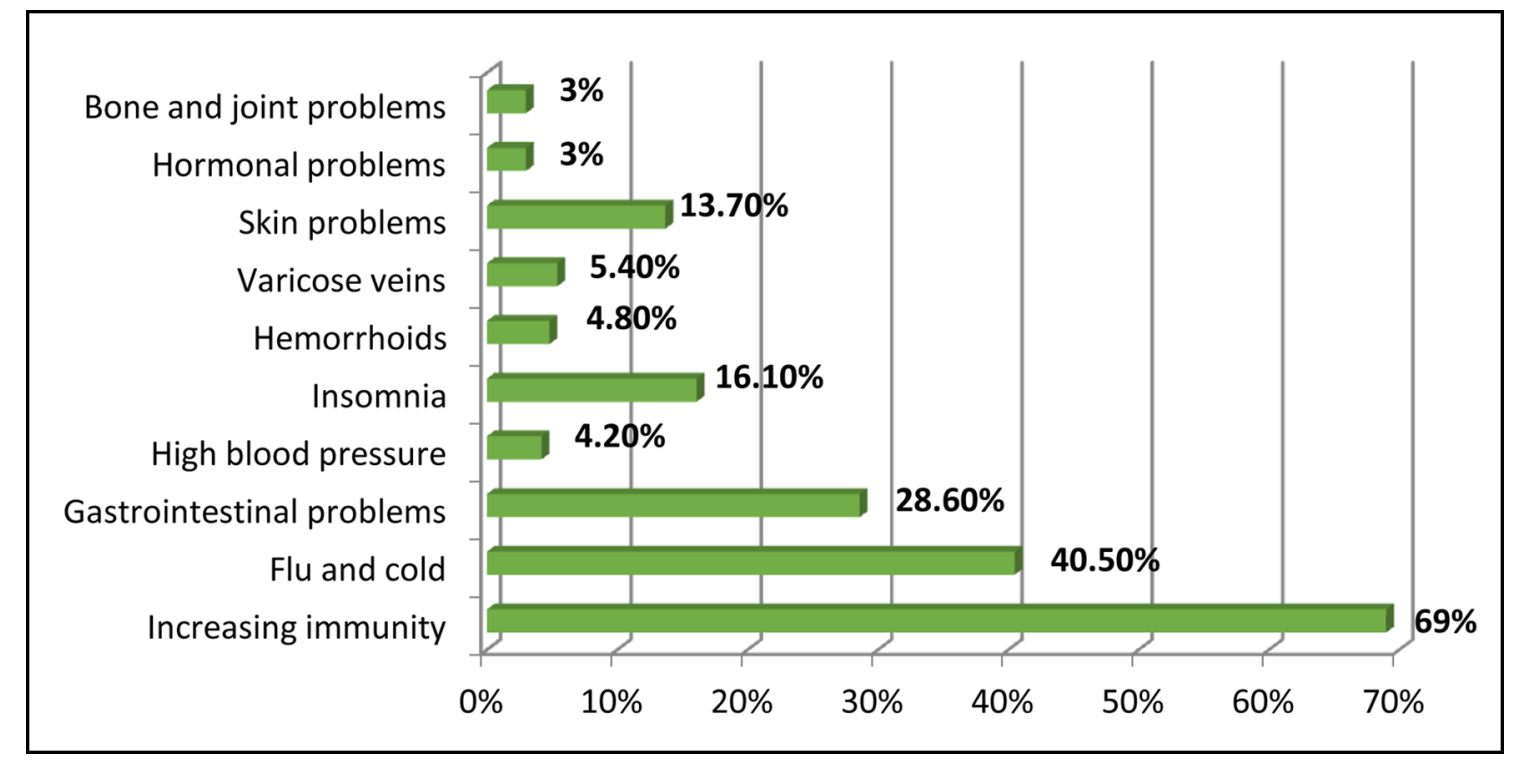

A significant proportion of respondents $(75.9 \%)$ had a positive attitude towards food supplements and herbal medicines. They thought that these products are of great benefit and effect (49\%), had no side effects (35.9\%). Only $22.9 \%$ of respondents reported that nutritional supplements and herbal medicines had a minimal benefit, and long-term intake was required. Data on the benefits and efficacy of taking herbal medicines and nutritional supplements are presented in Figure 5. 
Fig. 5. The benefits and efficacy of taking herbal and nutritional supplements

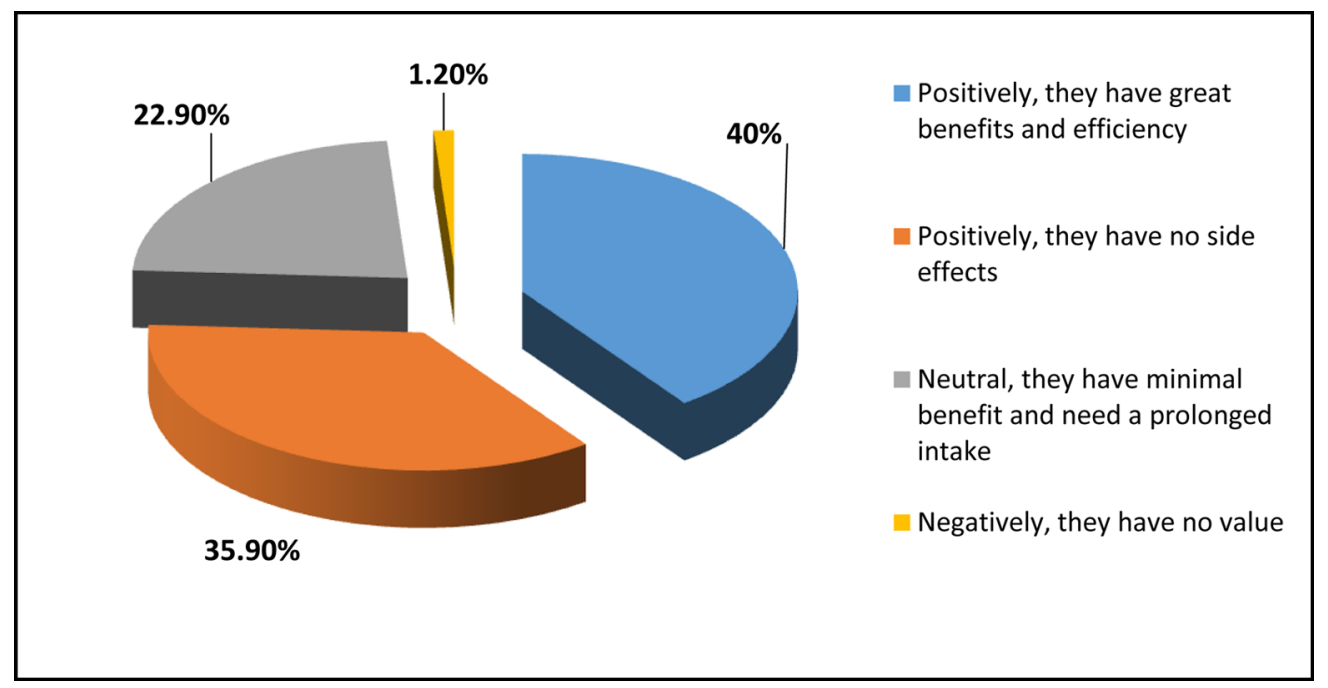

Before taking herbal and nutritional supplements, $40 \%$ of the respondents consulted a pharmacist; another $37.70 \%$ report consulted with a doctor; $8 \%$ said they were consulting both a doctor and a pharmacist. Only 5\% did not consult anyone. Data on consultations before taking herbal medicinal products and nutritional supplements are presented in Fig. 6.

Fig. 6. Consultations before taking herbal medicinal products and nutritional supplements

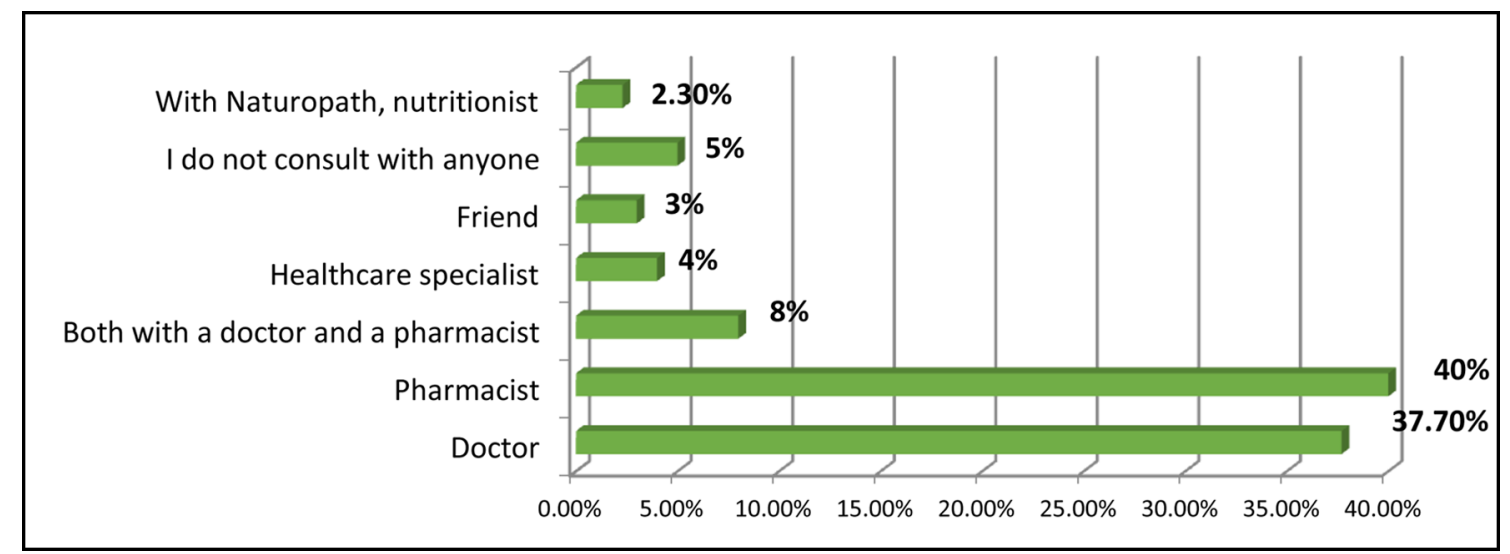

On the question "Are you interested in the possible interaction of herbal and nutritional products with other medicines you are taking?" $67.4 \%$ of users reported that being interested in the possible interaction of herbal and nutritional products with other medicines they took, only $4.7 \%$ answered they have never been interested. The data are presented in Fig. 7.

Fig. 7. Awareness of the possible interaction of herbal and nutritional products with other medicines

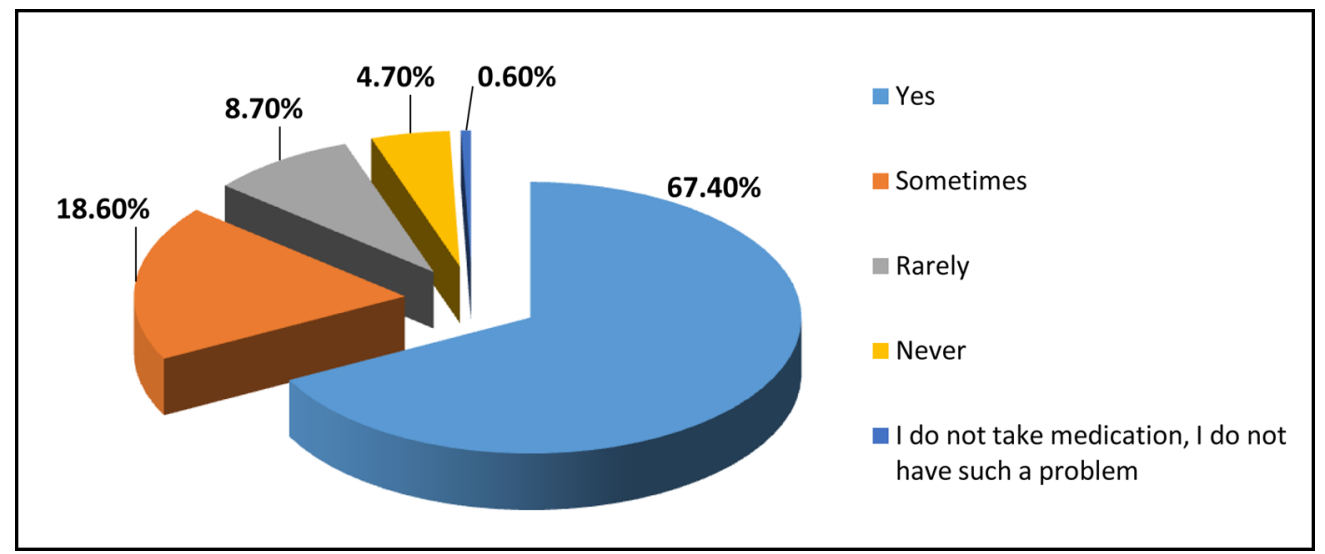


According to more than half of the users, the most important influence was the consultation with a doctor (52.9\%) and the consultation with a pharmacist $(51.2 \%)$, followed by a recommendation from a friend or relative (22.9\%). TV advertising had almost no impact on the choice of purchase among the respondents (4.7\%). The data are presented in Fig. 8 .

Fig. 8. The most powerful influence on buying herbal medicines and nutritional supplements

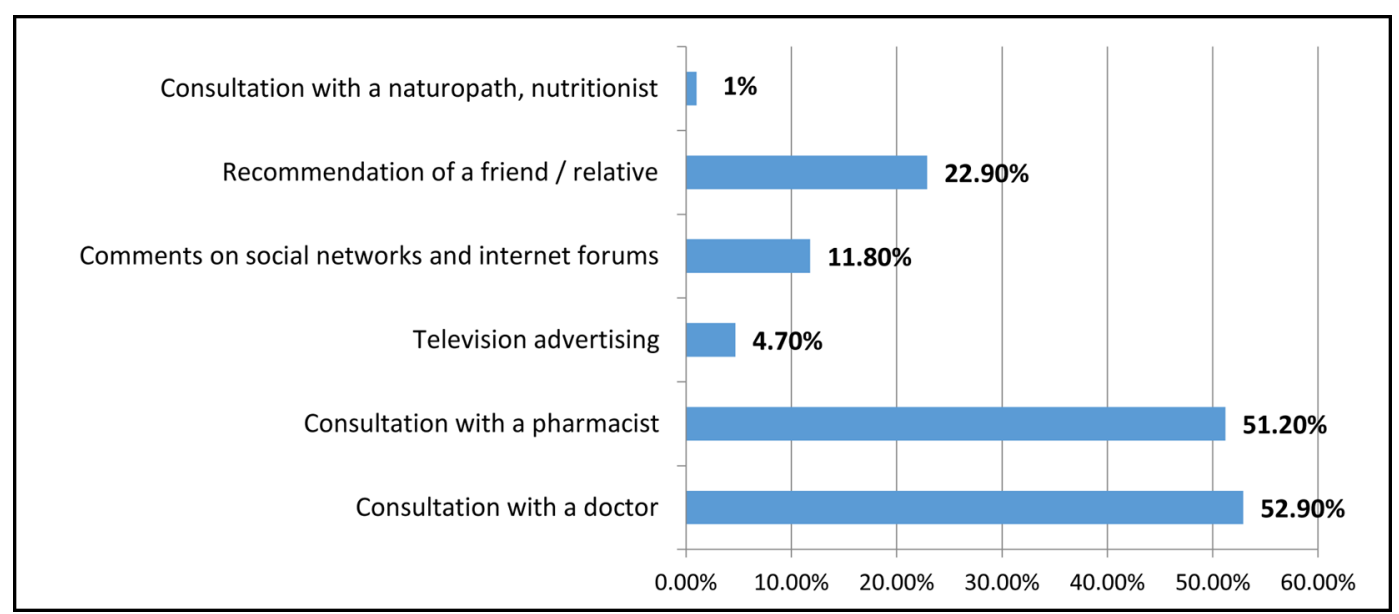

Consumers ranked the factors that most influence the decision to buy a specific herbal medicine and nutritional supplement in the following way: price $(54.5 \%)$ followed by the manufacturer $(47.9 \%)$ and the number of doses in multidose packs (27.3\%). The packaging has almost no effect on product selection (4.2\%). The data are presented in Fig. 9.

Fig. 9. Factors influencing the decision to buy a specific herbal medicine and nutritional supplement

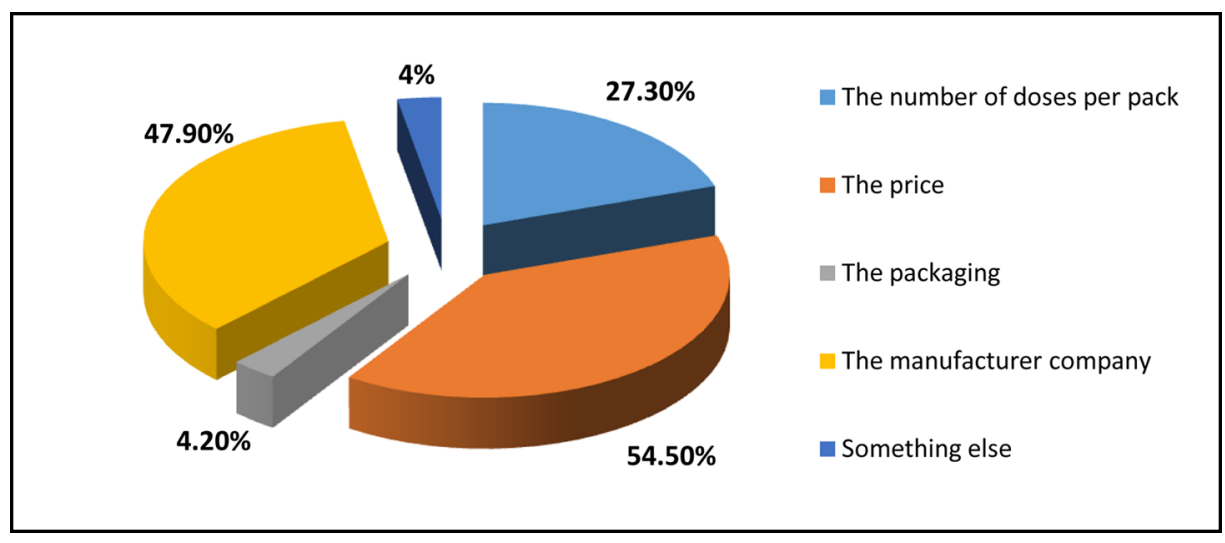

More than half of the respondents $(53.9 \%)$ preferred to buy products of foreign companies, Bulgarian products were preferred by $35.3 \%$ of the respondents. Only $6 \%$ chose as leading the quality of the product. The data are presented in Fig. 10

Fig. 10. Consumers preferences influence the buying of a specific herbal medicine and nutritional supplement

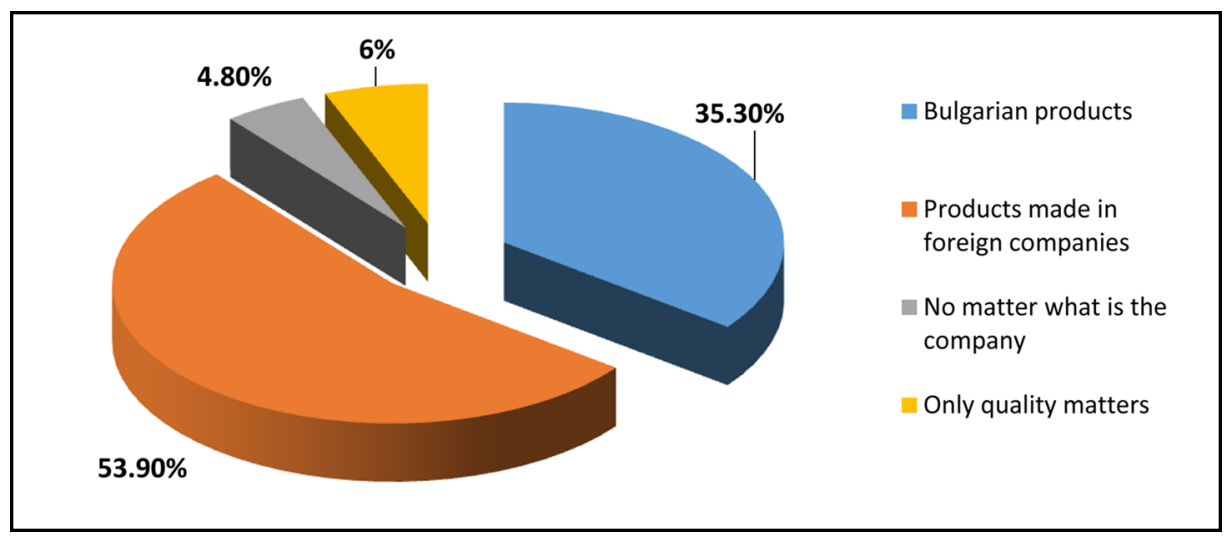


The most preferred drug form of herbal medicinal products and nutritional supplements for oral administration were tablets $(35.9 \%)$, followed by capsules $(25.9 \%)$, syrup $(21.8 \%)$, herbal extract (20\%), and only $7 \%$ of respondents preferred sachets. The data are presented in Fig.11.

Fig. 11. Preferred drug form of herbal medicinal products and nutritional supplements for oral administration

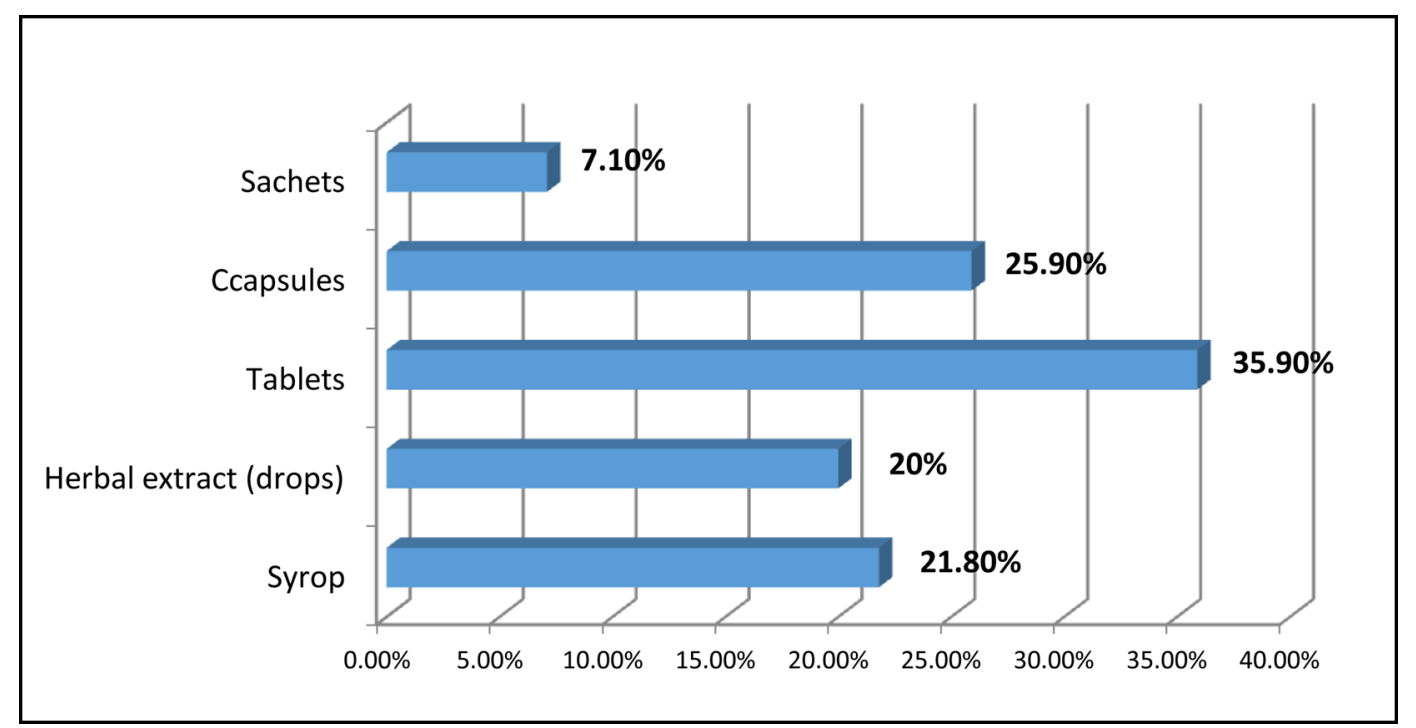

The most preferred herbal medicinal products for external use were those in the form of cream $(50.6 \%), 24.1 \%$ of respondents preferred aerosol, $18.2 \%$ gel and $16.5 \%$ oil. The data are presented in Fig. 12.

Fig. 12. Preferred drug form of herbal medicinal products and nutritional supplements for external use

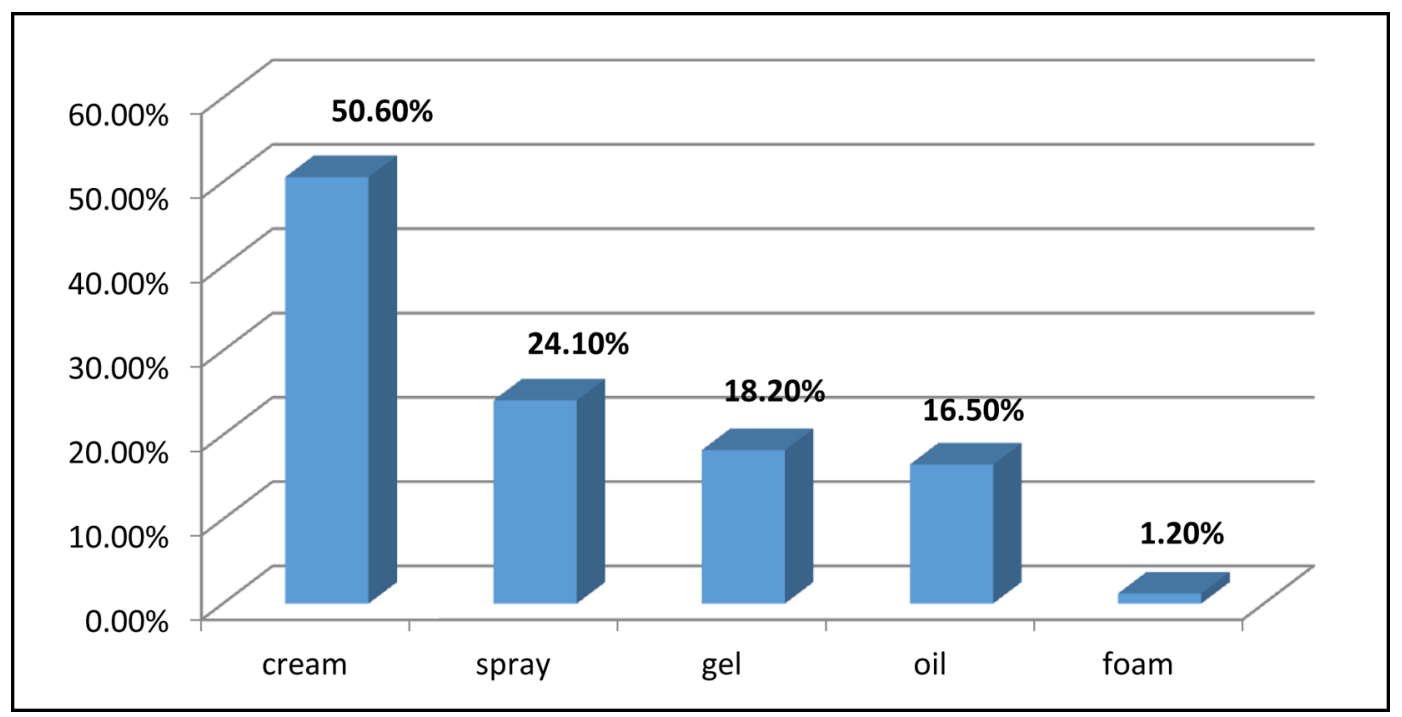

\section{DISCUSSION}

The majority of the interviewed participants were highly educated, aged 18-30 and they consumed herbal medicines and related products on recommendation by medical doctor or pharmacist.

There was a positive attitude towards food supplements and medicinal products of plant origin in a significant percent of the respondents $(75.9 \%)$. They believed that plant based supplements and products were of great benefit and effect (49\%), did not have side effects
(35.9\%). For $22.9 \%$ they had minimal benefit and longterm use was required.

Out of all respondents: $67,40 \%$ were interested in the possible incompatibility of herbal medicinal products and food supplements with other medicinal products, while $18,60 \%$ of participants were interested sometimes, $8,70 \%$ rarely, and only $4,70 \%$ never.

In most countries, including Bulgaria, herbal medicines and related products are introduced into the market without any mandatory safety or toxicological evaluation. 
Many benefits can be derived from the use of herbs and herbal supplements. Concerns remain about the possibility of product tampering and/or contamination, as well as a large number of possible interactions between medicines and herbal supplements. Mechanisms involved in herbdrug interactions are not fully understood, but both pharmacokinetics and pharmacodynamics processes may play a role.

\section{CONCLUSIONS}

Although nutritional supplements should not claim to have a healing effect on the body, more and more consumers use them in their daily lives to solve various health problems. The most common use of herbal medicines and supplements is in terms of boosting immunity, colds and flu, gastrointestinal problems and rarely for skin problems.

The factors that have an impact on the choice of herbal medicines and food supplements were the doctor's recommendation $(63.3 \%)$, the pharmacist's recommendation $(53.3 \%)$, the information brochure $(30.8 \%)$. Television advertising $(7.7 \%)$ Internet $(7.7 \%)$ and newspaper advertising $(4.7 \%)$ had little influence.

The positive attitude of the respondents towards them was due to the lack of data on side effects and the benefits they received. When buying herbal medicines and herbal dietary supplements, respondents consulted mainly with a doctor or pharmacist, but the price was also leading in the choice. Foreign products were more preferred than Bulgarian ones.

In order to achieve the rational use of herbal medicines and herbal dietary supplements, a better understanding of the impact of food supplements on patients must be a key priority. Without a doubt, the rational use of food supplements is associated with both a better knowledge of the disease and an increase in patients' awareness of the safety of the use of food supplements.

\section{REFERENCES:}

1. Petkova-Gueorguieva ES, Getov IN, Ivanov $\mathrm{KV}$, Ivanova $\mathrm{SD}$, Gueorguiev SR, Getova VI, et al. Regulatory Requirements for Food Supplements in the European Union and Bulgaria. Folia Med (Plovdiv). 2019 Mar 1;61(1):41-48. [PubMed] [Crossref]

2. Smith T, Kawa K, Eckl V, Morton C, Stredney R. Herbal Supplement Sales in US Increased $8.5 \%$ in 2017 , Topping \$8 Billion. HerbalGram. 2018; 119:62-71. [Internet]

3. European Food Safety Author- ity. Compendium of botanicals reported to contain naturally occuring substances of possible concern for human health when used in food and food supplements. EFSA Journal. 2012; 10(5):2663. [Crossref]

4. Asher GN, Corbett AH, Hawke RL. Common Herbal Dietary Supplement-Drug Interactions. Am Fam Physician. 2017 Jul 15;96(2):101-107. [PubMed]

5. Zhang J, Wider B, Shang H, Li e1002657. [PubMed] [Crossref]

Please cite this article as: Agova N, Petrova G, Georgieva S, Kumanov I. Consumers' Attitudes Towards the Use of Herbal Medicines and Herbal Supplements in Northeastern Bulgaria. J of IMAB. 2020 Jul-Sep;26(3):3278-3284.

DOI: https://doi.org/10.5272/jimab.2020263.3278

Received: 02/08/2019; Published online: 10/08/2020

\author{
Address for correspondence: \\ Galina Petrova \\ Medical University "Prof. Dr. Paraskev Stoyanov" Varna, Bulgaria \\ 55, Marin Drinov Str., 9002 Varna, Bulgaria \\ E-mail: galina.petrova@mu-varna.bg,
}

